\title{
REVIEW
}

\section{DICER1 gene mutations in endocrine tumors}

\author{
Michael Solarski', Fabio Rotondo², William D Foulkes ${ }^{3,4}$, John R Priest ${ }^{5}$, Luis V Syro6, Henriett Butz7, \\ Michael D Cusimano ${ }^{1}$ and Kalman Kovacs ${ }^{2}$
}

'Division of Neurosurgery, Department of Surgery, St. Michael's Hospital, Toronto, Ontario, Canada 2Division of Pathology, Department of Laboratory Medicine, St. Michael's Hospital, Toronto, Ontario, Canada

${ }^{3}$ Department of Human Genetics, Medicine and Oncology, McGill University, Montreal, Quebec, Canada

`Lady Davis Institute, Jewish General Hospital and Research Institute, McGill University Health Centre, Montreal, Quebec, Canada

${ }^{5}$ Department of Medicine, Minneapolis, Minnesota, USA

${ }^{6}$ Department of Neurosurgery, Hospital Pablo Tobon Uribe and Clinica Medellin, Medellin, Colombia

7Molecular Medicine Research Group, Hungarian Academy of Sciences, Semmelweis University, Budapest, Hungary

Correspondence should be addressed to F Rotondo: rotondof@smh.ca

\begin{abstract}
In this review, the importance of the DICER1 gene in the function of endocrine cells is discussed. There is conclusive evidence that DICER1 mutations play a crucial role in the development, progression, cell proliferation, therapeutic responsiveness and behavior of several endocrine tumors. We review the literature of DICER1 gene mutations in thyroid, parathyroid, pituitary, pineal gland, endocrine pancreas, paragangliomas, medullary, adrenocortical, ovarian and testicular tumors. Although significant progress has been made during the last few years, much more work is needed to fully understand the significance of DICER1 mutations.
\end{abstract}

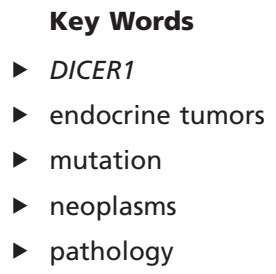

Endocrine-Related Cancer (2018) 25, R197-R208

\section{Introduction}

In the last few years, the DICER 1 gene and its mutations generated interest and have been investigated by several researchers. Results have shown that heterozygous germline DICER1 mutations cause a familial DICER1 tumor syndrome. This syndrome is characterized by a number of unusual tumors, both benign and malignant, such as pleuropulmonary blastoma (PPB), ovarian sex cordstromal tumors, ciliary body medulloepitheliomas, nasal chondromesenchymal hamartomas, multinodular goiter and differentiated thyroid carcinomas, among others (Foulkes et al. 2014). Prototypical renal manifestations of DICER1 mutation are cystic nephroma and, more rarely, anaplastic sarcoma of kidney. DICER1 mutations have also been documented in pediatric tumors including Wilms tumor and in pituitary blastoma (PitB), as well as in tumors of various endocrine organs (Hill et al. 2009, Huang \& Yao 2010, Schultz et al. 2011, Heravi-Moussavi et al. 2012, Darrat et al. 2013, de Kock et al. 2014a,b,c, 2017, Foulkes et al 2014, Costa et al. 2015, de Sousa et al. 2015). The rare pediatric PitB appears to be virtually pathognomonic for DICER1 mutations, which causes tumors in other endocrine organs as well (Fig. 1).

DICER1 is located on chromosome 14q32.13. It is composed of 27 exons and encodes a cytoplasmic class 3 ribonuclease (RNase-III), which plays a crucial role in the biogenesis of microRNAs (miRNAs). Human DICER1 protein, also known by several synonyms (Table 1) contains 1922 amino acids (Fig. 2). It cleaves doublestranded RNA precursors into small-interfering RNA (siRNA) and miRNA, both of which are evolutionarily 


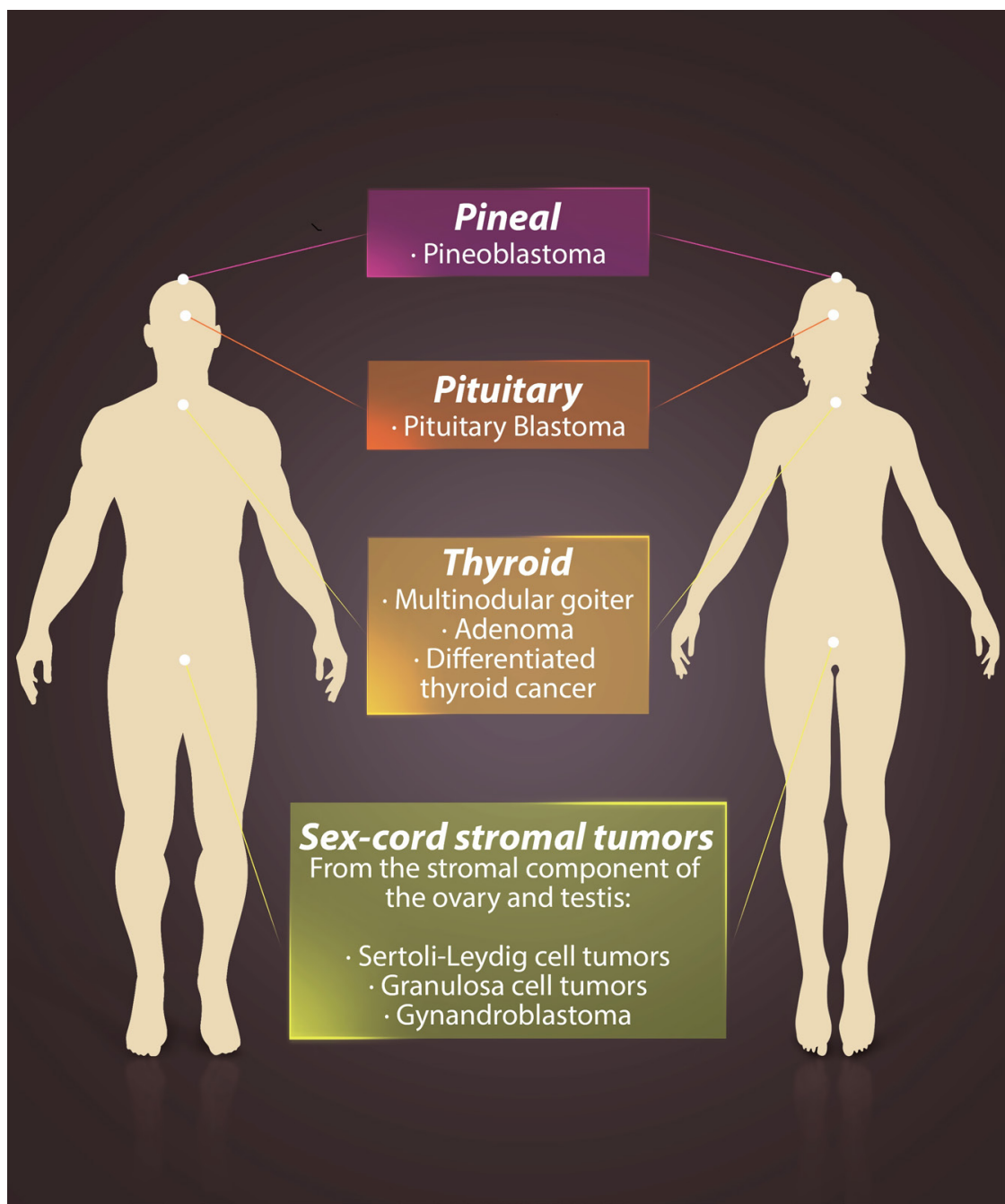

\section{Figure 1}

Schematic diagram of the various locations of endocrine tumors associated with DICER1 syndrome. A full colour version of this figure is available at https://doi.org/10.1530/ERC-17-0509.

conserved, small non-coding RNAs, approximately 21-23 nucleotides in length. siRNAs and miRNAs are incorporated into the RNA-induced silencing complex (RISC) and direct it to complementary RNAs, which cleave complementary target mRNA sequences using RNase. This process, known as RNA interference or gene silencing, prevents translation and thereby inhibits gene expression (Fig. 3) (Bernstein et al. 2001, Foulkes et al. 2014).

Endocrine tumors arise in hormone-producing cells of the endocrine glands which include the pituitary, thyroid, parathyroid, pineal body, adrenal cortex and medulla, ovaries and testes (Nicholson 2008). Recently, more evidence on the importance of DICER 1 role in tumors is emerging (Lambertz et al. 2010, Ravi et al. 2012, Foulkes et al. 2014). The present paper aims to review the role of DICER1 gene in endocrine cell tumors. Common bioinformatics resources for DICER1 syndrome are annotated in tabular form (Table 2).

\section{DICER1 mutations in thyroid tumors}

While tumors of the thyroid are the most common amongst the endocrine glands, it is not the most studied in relation to mutations in DICER1. Germline mutations in DICER1 have been found in individuals with multinodular goiter (MNG) (Rio Frio et al. 2011, Darrat et al. 2013, Rath et al. 2014, Rossing et al. 2014, Wu et al. 2014, Rutter et al. 2016). While MNG is not malignant, a few studies suggest that the rate of thyroid cancer may be 10-20\% higher in patients with DICER1 mutations with MNG (Smith et al. 2013). A 2011 study (Rio Frio et al. 2011) focusing on DICER1 mutations in familial MNG concluded that DICER1 mutations were responsible for autosomal dominant familial MNG and MNG with SLCT and that they do not need to coexist with PPB. miRNA analysis of lymphoblastoid cell lines from affected and unaffected familial MNG cases revealed DICER1 mutation carriers had deviations in their miRNA 
Table 1 Synonyms and previous nomenclature for the DICER1 gene used in the literature.

DICER1
DCR1
Dicer
Dicer 1 ribonuclease III
Dicer 1, double-stranded RNA-specific endoribonuclease
Dicer 1, ribonuclease type III
Dicer1, DCR-1 homolog
DICER1_HUMAN
Endoribonuclease dicer
Helicase MOI
Helicase-moi
Helicase with RNAse motif
HERNA
K12H4.8-LIKE
KIAA0928
MNG1

(Rio Frio et al. 2011). Although studies have focused on the possible existence of a correlation between DICER1 mutations, MNG and thyroid cancer, that link is not clear. Specifically, some differentiated thyroid carcinoma (DTC) may not arise from MNG and the risk of DTC given that an individual has MNG is unknown.

Recent studies have provided more direct links between DICER 1 mutations and thyroid cancer. In a case series of three patients with DTC and PPB, acquired somatic DICER1 mutations in thyroid tissue, accompanied by inherited germline mutations in DICER1 were identified (de Kock et al. 2014c). The somatic mutations in these individuals were hotspot mutations, interfering with metal ioncoordinating residues in the RNase IIIb domain of DICER1, which have also been observed in other individuals with DTC and germline DICER1 mutations (Rutter et al. 2016). Somatic hotspot mutations (E1813G, E1813K, $\mathrm{D} 1810 \mathrm{H}$ ) have also been observed in papillary thyroid carcinoma (PTC) without germline DICER1 mutation and are predicted to have a high impact on the function of the DICER1 protein (Agrawal et al. 2014, Costa et al. 2015, Landa et al. 2016). In a study of sporadic follicular thyroid cancers, two minimally invasive follicular thyroid carcinomas (miFTC) and two benign follicular adenomas (FA) were found to carry somatic mutations in DICER1 (Yoo et al. 2016). These mutations (E1705Q, D1810H, E1813G and E1813Q) were also found to be in the RNase III domain. DICER1 mRNA downregulation and altered expression of miRNAs have been observed in benign and malignant thyroid samples, including follicular adenomas and PTC as well (Erler et al. 2014).

The risk of DTC is modestly elevated with the existence of DICER 1 mutations but in a 2012 publication, they reported the development of follicular thyroid carcinoma after the patients were treated for PPB using both high-dose chemotherapy (HDC) and hematopoietic stem cell transplantation (HSCT) (Shin et al. 2012). Although literature is limited, they found that there was a particularly high prevalence rate (60\%) of follicular thyroid carcinomas in patients with PPB with a DICER1 mutation, who were treated with HDC and HSCT. It is known that genetic anomalies, as well as, chemotherapies and radiotherapies contribute to the development of secondary thyroid carcinomas, but this study found that using HDC and/or HSCT treatments can increase the susceptibility for patients with PPB to develop secondary follicular thyroid carcinoma (Cohen et al. 2007, Taylor et al. 2009, Shin et al. 2012).

To date, the role of DICER1 mutations in thyroid cancer remains understudied and warrants further analysis, especially given the prevalence of thyroid cancers in the population.

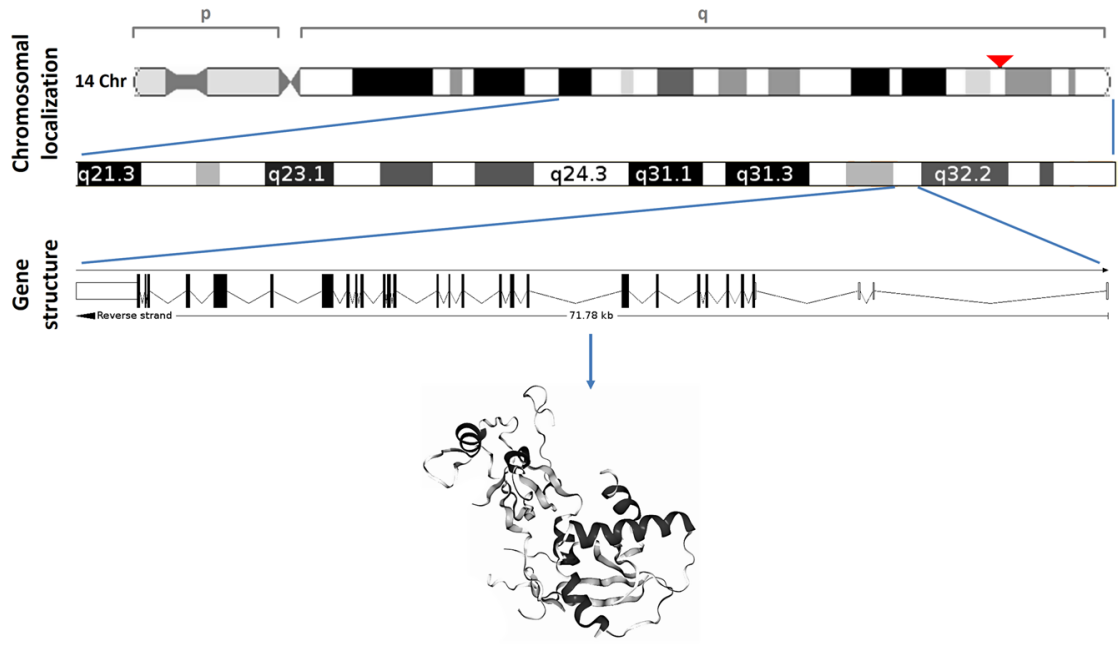

Figure 2

Schematic diagram of the role of DICER1 in miRNA processing. The function of the DICER1 gene is to cleave double stranded RNA precursors into small interfering RNA (siRNA) and miRNA both of which are evolutionally conserved, small non-coding RNAs approximately 21-23 nucleotides in length. A full colour version of this figure is available at https://doi.org/10.1530/ ERC-17-0509. 


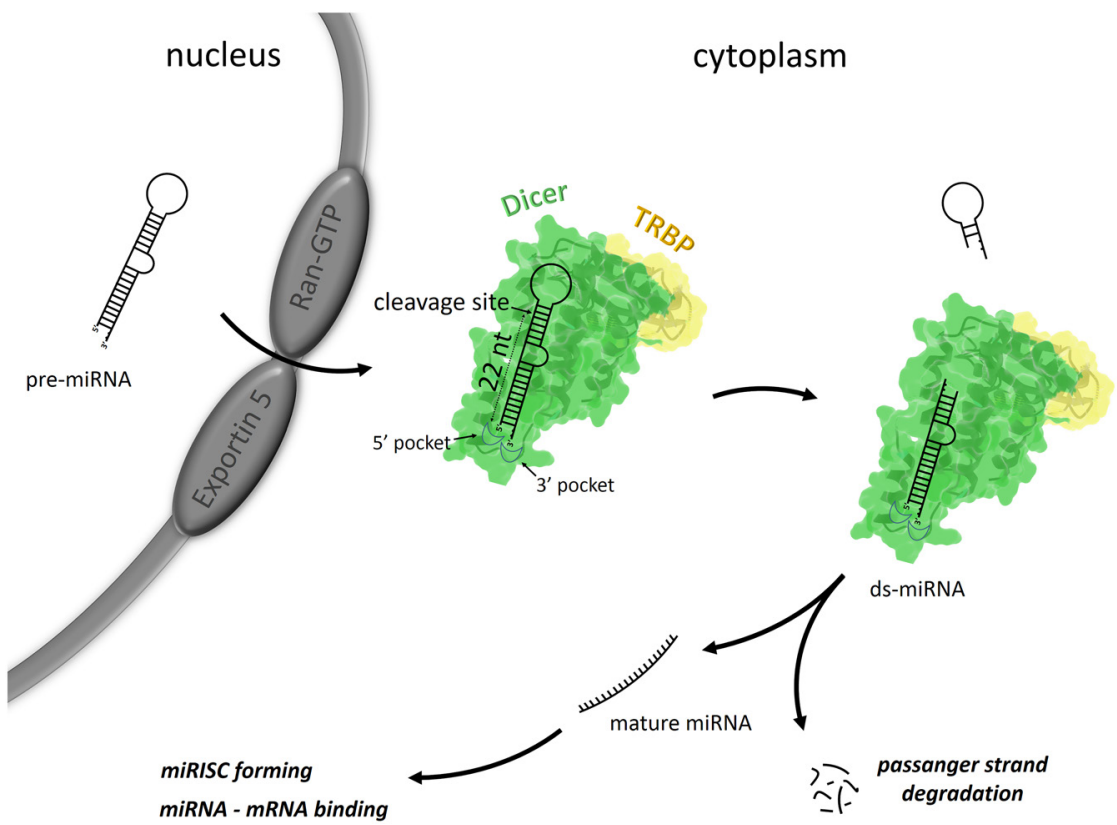

\section{Figure 3}

The cytogenetic location of the DICER1 gene is on the long arm of chromosome 14 at position 32.13. A full colour version of this figure is available at https://doi.org/10.1530/ERC-17-0509.

\section{DICER1 mutations in ovarian and testicular cancer}

An extensive amount of research revealed the relationship between DICER1 mutations and ovarian tumors of nonepithelial and stroma-cell origin (de Kock et al. 2017). There has been considerably less work performed to examine this relationship in gonadal tumors of endocrine origin (Kim et al. 2013, Schultz et al. 2014). This is likely due to the fact that these types of tumors represent a small fraction of gonadal cancers (Winter \& Albers 2011, Van Nieuwenhuysen et al. 2013). Additionally, to our knowledge, all research performed in this area has focused on ovarian tumors, with little to no work performed on tumors of testicular origin.

Research on DICER1 in endocrine gonadal tumors began with the observation that there were an unusually high number of individuals with ovarian sex-cord stromal tumors (OSCST) and familial cases of other lesions associated with DICER1 syndrome. Schultz and coworkers identified several cases of OSCST in individuals with familial PPB, which is known to be associated with DICER1 germline mutations (Hill et al. 2009, Schultz et al. 2011). They identified four DICER1 mutations in six patients with OSCST with family history of PPB and two mutations in patients without PPB kindreds. These DICER1 mutations were observed in three different types of OSCST: Sertoli-Leydig cell tumors (SLCT), juvenile granulosa cell tumors and gynandroblastoma. It was also observed that some families with cases of MNG also contained individuals with SLCT (Rio Frio et al. 2011,
Darrat et al. 2013, Wu et al. 2014). Germline DICER1 mutations were observed in both familial MNG and MNG with SLCT studied. It was also shown that miRNA profiling RNA samples from lymphoblastoid cell lines from both affected and unaffected members of familial MNG cases revealed miRNA perturbations in those individuals (Rio Frio et al. 2011, Kim et al. 2013, Schultz et al. 2014, Wu et al. 2014). A study by Kim and coworkers demonstrated how OSCSTS harbored DICER1 mutations that were rarely found in other tumors (Kim et al. 2013).

Further research examined the effects of DICER1 mutations in non-epithelial ovarian cancers and identified so-called 'hotspot' mutations in the DICER1 RNase IIIb domain in 29\% of non-epithelial ovarian tumors (Heravi-Moussavi et al. 2012). These mutations were most frequently encountered in Sertoli-Leydig cell tumors (60\%) and exclusively affected RNase IIIb function without impairing RNase IIIa function. In their study, they also screened testicular germ-cell tumors to determine whether they also had the same mutations. They found that only one testicular germ-cell tumor harbored the same hotspot mutations noted in the nonepithelial ovarian tumor types screened (Heravi-Moussavi et al. 2012). Hotspot mutations affected the $\mathrm{D} 1709$ residue in codons encoding metal-ion $\left(\mathrm{Mg}^{2+} / \mathrm{Mn}^{2+}\right)$ binding sites, which aid in the interaction and cleavage of miRNA. Notably, DICER1 function was not completely lost in these tumors, but was altered in specific cell types. An absence of LOH argues against the role of DICER1 as a two-hit tumor suppressor and suggests it acts more like a dominantly acting oncogene (Heravi-Moussavi et al. 
Table 2 Bioinformatic resources for DICER1 syndrome.

\begin{tabular}{ll}
\hline $\begin{array}{l}\text { Gene and genome } \\
\text { Ensemble }\end{array}$ & http://www.ensembl.org/Homo_sapiens/Gene/Summary?db=core;g=ENSG00000100697;r=14:95086228- \\
& $95158010 ;$ t=ENST00000343455 \\
NCBI gene & https://www.ncbi.nlm.nih.gov/gene/23405 \\
HGNC & https://www.genenames.org/cgi-bin/gene_symbol_report?hgnc_id=HGNC:17098 \\
GeneCards & http://www.genecards.org/cgi-bin/carddisp.pl?gene=DICER1 \\
Protein & \\
UniProt & http://www.uniprot.org/uniprot/Q9UPY3 \\
STRING & https://string-db.org/cgi/network.pl?taskId=z7cZyhER4Ky5 \\
Human protein atlas & https://www.proteinatlas.org/search/DICER1 \\
HPRD & http://hprd.org/summary?hprd_id=05875\&isoform_id=05875_1\&isoform_name=Isoform_1 \\
Clinical resources & \\
OMIM & https://www.omim.org/entry/606241?search=dicer1\&highlight=dicer1 \\
GeneReviews & http://www.ncbi.nlm.nih.gov/books/NBK196157/
\end{tabular}

HGNC, HUGO Gene Nomenclature Committee; HPRG, Human Protein Reference Database; NCBI, National Center for Biotechnology Information; OMIM, Online Mendelian Inheritance in Man; STRING, Search Tool for the Retrieval of Interacting Genes/Proteins; UniProt, Universal Protein Resource.

2012). At present, it is debatable as to the exact mechanism of DICER1 function. In certain tumors, the LOH may be a result of the presence of a germline mutation in DICER1, which is accompanied by a somatic mutation in RNase IIIb domain or it may result in an autosomal dominant pattern whereby only one copy of the altered gene is sufficient to cause the increased risk of developing the tumor. The finding of hotspot mutations in SLCT was confirmed by Kim and coworkers, albeit at a lower rate (15.4\%) (Kim et al. 2013). These mutations were absent in all other non-epithelial ovarian tumors examined, including sex cord-stromal tumors and granulosa cell tumors. A similar study found DICER1 somatic mutations in $32 \%$ of sex cord-stromal tumors and 3\% of germ cell tumors (Witkowski et al. 2013). These mutations only affected five residues (E1705, D1709, E1788, D1810 and E1813) all within the RNase IIIb domain. SLCT were the most common tumors affected by these mutations (53\%). Goulvent and coworkers observed mutations in the RNase IIIb domain in $31.5 \%$ of SLCTs, $25 \%$ of juvenile granulosa cell tumors and $8.3 \%$ of undifferentiated SCSTs (Goulvent et al. 2016). Although this study comprised a small sample (156 SCLTs), they found that more frequent expression of the estrogen receptor and lower age at diagnosis were observed in DICER1-mutated tumors, suggesting that DICER1-mutated tumors may have a worse prognosis than DICER1 wild-type tumors.

Analysis of global miRNA and gene expression in SLCTs with DICER1 hotspot mutations revealed a global reduction of 5 -derived miRNAs due to loss of catalytic activity of the RNase IIIb domain (Wang et al. 2015). This deficit in miRNA production was associated with deregulation of genes controlling cell proliferation (ARID3A, CDC25A and PLAGL1) and cell differentiation
(FST, CYP19A1, FGF9 and FGFR2). Silencing of the expression of the let-7 family of miRNA, which have important roles in cell proliferation and differentiation, was proposed to contribute to the tumorigenesis of SLCTs. It is important to note that SLCTs are rare SCSTs that account for $0.5 \%$ of all ovarian neoplasms. They are the most virilizing tumor of the ovary and approximately 50\% have been shown to be endocrine-inactive tumors, but no data are available to show what percentage of DICER1 mutation-positive cases are functioning (GheorghisanGalateanu et al. 2003).

The histologic features of OSCSTs with DICER1 mutations have not been studied extensively, but appear to have some distinctive features including Sertoli cell and juvenile granulosa cell-like elements (Oost et al. 2015). However, even with identical mutations, tumor morphology and immunohistochemical properties can vary drastically, suggesting that other factors are involved. More extensive studies are required to fully understand how DICER1 mutations contribute to the histologic features of OSCSTs.

Current research on DICER1 in gonadal tumors is aimed at not only finding new therapeutic approaches, but also aiding in the classification of problematic or previously unclassifiable OSCSTs, in particular, prognostic information, as that is a key evidence in any cancer consultation (Stewart et al. 2013, Witkowski et al. 2013). The absence of DICER1 mutations in unclassified SCSTs may suggest the existence of distinct tumor subtypes with different mechanisms of pathogenesis (Stewart et al. 2013). Wang and coworkers found that SLCTs with DICER1 hotspot mutations frequently presented with various levels of retiform foci, which are typically seen in moderately and poorly differentiated SLCTs (Wang et al. 2015). http://erc.endocrinology-journals.org https://doi.org/10.1530/ERC-17-0509 (c) 2018 Society for Endocrinology Published by Bioscientifica Ltd. Printed in Great Britain 
In addition, SLCTs with hotspot mutations have distinct gene expression landscapes and may represent distinct diseases with different patient outcomes. Improvement of diagnosis accuracy and reclassification of SLCTs may occur in the future, as the genomic alterations in these types of tumors are better understood.

\section{DICER1 mutations in pituitary tumors}

Neoplasms of the pituitary gland are not uncommon in the general population. Pituitary adenomas have an incidence of up to $15 \%$ of all intracranial tumors (Osamura et al. 2017). First described in 2008, pituitary blastomas (PitB), on the other hand, are exceedingly rare embryonal tumors of the pituitary gland, which typically occur in very young children (Scheithauer et al. 2008, 2012).

To date, the only pituitary lesion reported to be associated with DICER1 mutations is PitB. In 2012, Scheithauer and coworkers described a case of a 9-month infant with PitB and a germline heterozygous DICER1 mutation (Scheithauer et al. 2012). A subsequent study examined germline DICER1 mutations in nine additional children with PitB (de Kock et al. 2014b) - germline DNA from 10 children with PitB was analyzed, nine of which harbored germline DICER1 mutations, with one affecting the RNase IIIb catalytic site, a domain critical to its function. PitB tumor DNA analyzed from these 10 patients demonstrated that of nine that had DICER1 mutations, eight were somatic. Seven of these mutations were predicted to affect the RNase IIIb catalytic site. The other mutations were loss of heterozygosity $(\mathrm{LOH})$ of the wild-type allele (de Kock et al. 2014b).

Using tumor tissue from a 12-month-old female with an aggressive PitB and resultant Cushing's disease, Sahakitrungruang and coworkers performed whole-exome sequencing (WES) and Sanger sequencing of DICER1 from genomic DNA (Sahakitrungruang et al. 2014). This study identified two novel DICER1 mutations in the DNA of the PitB: a heterozygous germline c.3046delA $\rightarrow$ (p.S1016VfsX1065) frameshift mutation and a heterozygous somatic c.5438A3T $\rightarrow$ (p.E1813V) missense mutation. The p.E1813V mutation was located in RNase IIIb catalytic domain. Given that two mutations exist in the tumor DNA, one germline and the other somatic, these findings suggest that loss of function of both DICER1 alleles is required for tumor development.

A striking characteristic amongst patients with PitB is that they present with features of Cushing disease, with elevated levels of blood ACTH and hypercortisolism. It was also noted that apart from the characteristic features found in many of the PitB cases, they can also coexist with PPB and cystic nephroma (Scheithauer et al. 2012, de Kock et al. 2014b, Rotondo et al. 2017)

Obviously, more work must be performed to understand the role of DICER1 mutations in PitB. However, the current evidence suggests that germline DICER1 mutations are a major contributor to the development of PitB, along with a second acquired somatic mutation in the RNase IIIb domain. Such a 'two-hit' model of tumor development is the hallmark of many types of human cancers and appears to be characteristic of DICER1 mutations in PitB.

\section{DICER1 mutations in pineal gland tumors}

Several investigations have been done into the role of DICER1 mutations in the pineal gland. Current research suggests that DICER1 mutations may contribute to the development of pineoblastoma (PinB), a malignant, primitive neuroectodermal tumor of the pineal gland, typically occurring in children.

In one patient with a malignant PinB, a mutation in exon 8 of the DICER1, c.1128_1132delAGTAA, was identified in genomic DNA isolated from the tumor (Sabbaghian et al. 2012). This mutation was expected to cause p.Lys376Asnfs* 11 , a deleterious change to the protein and was present in the tumor in the hemizygous state, but was heterozygous in the germline, suggesting that there was LOH at the DICER1 locus in the tumor (Sabbaghian et al. 2012).

A more recent study by de Kock and coworkers extended the previous finding of the presence of DICER1 mutations in patients with PinB (de Kock et al. 2014a). In 21 cases, six deleterious DICER1 mutations were identified. Three of these mutations (c.4754C $>$ g, p.(Ser1585*), c.5103C >A, p.(Tyr1701*), c.4633dupT, p.(Ser1545Phefs*7)) were germline in origin and were predicted to prematurely truncate the protein. Two of these mutations were accompanied by LOH of the wildtype allele. Another case demonstrated two nonsense mutations, c.3280_3281delTT (p.(leu1094Argfs*9)) and c.3675C>g (p.(Tyr1225*)), which could not be identified as somatic or germline but were also predicted to prematurely truncate the protein. Another germline mutation, c.1498A $>\mathrm{T}(\mathrm{p}$. (Lys500*)), induced a premature stop codon in the helicase domain-encoding sequence of the gene and was accompanied by $\mathrm{LOH}$ of the wildtype allele. Somatic analysis was not available for the last two mutations, but germline analysis revealed a c. $4050+1 \mathrm{~g}>\mathrm{A}$ germline DICER1 variant in one case and 
a (c.4407_4410delTTCT, p.(Ser1470leufs*19)) mutation in the other. None of the mutations encountered in this study affected the DICER1 RNase IIIb domain. Based on their findings, the authors suggest that DICER1 is an important susceptibility gene for PinB and that the means by which the second allele is inactivated may be different from other DICER1-related tumors (de Kock et al. 2014a).

In a retrospective study examining patients with pineal parenchymal tumors (PPTs), seven cases of PinB were studied (Raleigh et al. 2017). In one pediatric patient, two inactivating mutations in DICER1 were identified (p.V1080fs, p.E1813D). These mutations were found in the genomic DNA of the tumor, but were not present in DNA isolated from the patient's blood, suggesting they were somatic in nature. The authors suggest that, in addition to DICER1 tumor predisposition syndrome, DICER1 inactivation and miRNA deregulation may contribute to the pathogenesis of sporadic PinB (Raleigh et al. 2017).

Similar to PitB, the current research on DICER1 mutations in PinB seems to suggest a 'two-hit' model of tumorigenesis. As suggested by de Kock and coworkers, however, the means by which the second allele is inactivated may be different from other DICER1-related tumors (de Kock et al. 2014a). The mechanism involved in the inactivation of the second allele in PinB involves an inactivating germline mutation and a subsequent somatic hot-spot mutation in certain nucleotides affecting the RNase IIIb domain (de Kock et al. 2014a). It is important to note, however, that a germline mutation is not necessary for tumor production, since PinB can arise because of a somatic mutation which leads to inactivation of DICER1 and dysfunction/regulation of miRNA (Raleigh et al. 2017). Of course, with only three studies conducted on this topic so far, there is much to be learned about how inactivation of the DICER1 and miRNA dysfunction leads to tumor growth in the pineal gland.

\section{DICER1 mutations in cancer of the endocrine pancreas}

A number of publications have examined the role of DICER 1 in the developing and mature pancreas, as well as the relationship between DICER1 gene mutations and diabetes. It is evident from these studies that DICER1 plays a crucial role in the development and maintenance of the adult pancreas (Lynn et al. 2007, Morita et al. 2009, Tattikota et al. 2011, Kanji et al. 2013, Wang et al. 2014, Özcan et al. 2015). The regulatory activity by DICER is crucial for the preservation of normal acinar cell differentiation and that homozygous DICER deletion leads to the loss of acinar cell polarity, which initiates both epithelial-to-mesenchymal transitions and acinarto-ductal metaplasia (Wang et al. 2014). Additionally, it has been demonstrated that interference with DICER1/miRNA signaling may lead to defects in insulin signaling and glucose metabolism, perhaps identifying a novel therapeutic target for diabetes mellitus (Kalis et al. 2011, Melkman-Zehavi et al. 2011, Locke \& Harries 2012, Mandelbaum et al. 2012, Abuhatzira et al. 2015).

Few studies have examined the role of DICER1 in endocrine pancreatic cancer and the exocrine pancreas (Morris et al. 2014). In mice, homozygous knockout of Dicer1 was demonstrated to initiate epithelial-tomesenchymal transition (EMT) and acinar-to-ductal metaplasia (ADM) in pancreatic acinar cells (Wang et al. 2014). Simultaneous activation of oncogenic Kras, a small GTPase known to promote pancreatic neoplasia (Eser et al. 2014), with heterozygous knockout of the Dicer1 accelerated the initiation of pancreatic intraepithelial neoplasms (PanIN) (Wang et al. 2014). Conversely, Kras activation combined with homozygous knockout of Dicer1 did not affect the rate of PanIN initiation but caused accelerated ADM formation (Wang et al. 2014). In contrast, they also found that in the absence of Kras activation following widespread Dicer1 deletion, acinar cells were permitted to regenerate. Although this was a significant finding, it cannot be excluded that other factors such as a transdifferentiated and/or a progenitor cell population may have contributed to this regeneration of cells within the pancreas (Criscimanna et al. 2011, Wang et al. 2014) These findings reveal that tumor growth in the exocrine pancreas may be sensitive to DICER1 dosage. Since few studies have focused in this area, further work is necessary to eliminate any potential technical limitations (difficulty attaining complete loss of Dicer or the fact that Dicer $1^{\mathrm{fl} / \mathrm{fl}}$ animals retain one functional Dicer1 allele) (Wang et al. 2014), in order to confirm the role of DICER1 in pancreatic cancer. In a number of pancreatic cancer cell lines (BxPC-1, Capan-2, Panc-1), Wang and coworkers systematically knocked down DICER1 expression and observed the effects on oncogene and tumor suppressor gene expression (Wang et al. 2012). Variable expression profiles of the Kras oncogene and the p53 and PTEN tumor suppressors were observed in the three cell lines when Dicer1 was knocked out. Dicer1 knockdown inhibited BxPC-1 tumor growth but promoted Panc-1 tumor growth while having no effect on Capan-1 tumor growth. Clearly, there are different molecular mechanisms involved in the pathogenesis of various pancreatic cancer subtypes, 
highlighting the necessity for individualized therapies (Wang et al. 2012).

Whether or not these findings will translate to cancers of the endocrine pancreas is yet to be seen. While further investigation may be thwarted by the scarcity of pancreatic cancers of endocrine origin, it is clear that more work must be performed in order to determine if the DICER 1 is a viable therapeutic target.

\section{DICER1 mutations in medullary and adrenocortical tumors}

In the last decade, genomic approaches have been successfully applied to adrenocortical and medullary tumors. Exome sequencing identified new major drivers in all tumor types (Espiard et al. 2014, Faillot \& Assie 2016). Although a substantial amount of research has been conducted in order to determine the role of DICER 1 in the adrenal gland, to our knowledge, there have been no studies identifying DICER1 mutations in tumors of the adrenal medulla. Studies have mainly focused on the role in the development, maintenance and function of the adrenal medulla and adrenal cortex (Huang \& Yao 2010, Huang et al. 2012, Krill et al. 2013, Robertson et al. 2013).

Only one study, to our knowledge, has examined DICER 1 mutations in adrenocortical cancer. de Sousa and coworkers examined a large cohort of adult adrenocortical tumors (ACT) and found no hotspot mutations in 31 adrenal adenomas and 30 adrenal carcinomas (de Sousa et al. 2015). Whether or not there were other mutations present is unknown, since only the RNase IIIb domain was sequenced. These authors, however, did find that DICER1 gene and expression was higher in 51\% of adrenocortical carcinomas than in the adenomas studied. When the authors studied the data of the adrenocortical carcinomas alone, they found that a weak DICER1 expression was correlated with reduced disease-free and overall survival time, larger tumor size, more advanced staging, higher Weiss score and was a predictor of recurrence in adrenocortical carcinomas (ACC) (de Sousa et al. 2015). In a similar study, Caramuta and coworkers demonstrated that the DICER1 was overexpressed in adrenocortical carcinomas compared to adrenocortical adenomas (Caramuta et al. 2013). The reason for this discrepancy is unclear and needs further research.

A 2013 study by Caramuta and coworkers investigated the clinical and functional impact of TARBP2 overexpression in adrenocortical carcinomas since it was found that mutations both truncating and framshift in TARBP2, a gene which encodes transactivation response
(TAR) RNA-binding protein (TRBP) protein, causes diminished TRBP protein expression and a defect in miRNA processing (Melo et al. 2009, Caramuta et al. 2013). They found that in adrenocortical carcinomas, TRBP was overexpressed and that expression of the TARBP2 gene was a useful marker to differentiate between adrenocortical adenomas and carcinomas (Caramuta et al. 2013). TRBP interacts directly with the DICER1 protein and is essential for the stabilization of the DICER1 protein (Chendrimada et al. 2005). The coupling of TRBP with DICER1 is essential for the recruitment of the argonaute 2 (Ago2), an enzyme required by RISC, which targets mRNA to prevent translation (Chendrimada et al. 2005).

The lack of research on DICER1 mutations in adrenocortical cancer likely reflects the fact that adrenocortical cancer has an annual incidence of only 0.5-2 cases per million population (Terzolo et al. 2014). With the rarity of ACC and the relatively recent surge in interest of DICER1, it is no surprise that few papers have been published on this topic. However, the presence of DICER1 mutations in many endocrine cancers calls for more research on DICER1 mutations in the adrenal gland, given the devastating nature of the disease and lack of efficacious treatments (Terzolo et al. 2014). Whether or not DICER1 mutations are present in adrenocortical cancer remains to be seen, but they could present a muchneeded therapeutic target for this disease.

\section{DICER1 mutations in paragangliomas}

Similar to other endocrine tumors, paragangliomas are uncommon neoplasms, with an annual incidence of 1 in 1.3 million, and metastases has been documented as occurring in only 1-3\% of cases (Zak \& Lawson 1982, Mertens et al. 1993, Trombetta et al. 2008). Considerable progress in the understanding of the genetic basis of paragangliomas has been made and many familial forms have been recognized (Toledo \& Dahia 2015).

To date, and to our knowledge, there have been no studies undertaken to examine the role of DICER1 mutations in paragangliomas, likely due to the low prevalence of paragangliomas in the population. However, other genes have been implicated in the pathogenesis of paraganglioma (Kirmani \& Young 2008, Lloyd 2011). The discovery of these mutations has led to a better understanding of the pathogenesis of paragangliomas and their prevalence in families. Whether or not a similar discovery will be made with DICER1 mutations is unknown. Unfortunately, this group did not investigate DICER1 mutations in this endocrine tumor type. 
Literature on paragangliomas has focused on describing and characterizing this particular tumor type and no research group, to our knowledge, has looked at whether DICER1 mutations plays a role in the development and/or progression of paragangliomas in humans. It is therefore also worthy of future research given the presence of these mutations in other endocrine tumors.

\section{DICER1 mutations in parathyroid tumors}

While the role of wild-type DICER1 has been shown to be necessary for the normal function of the parathyroid in response to hypocalcemia and uremia (Shilo et al. 2015), there have been no studies examining the role of DICER1 mutations in the pathogenesis of parathyroid tumors despite the fact that parathyroid tumors are quite prevalent and many are asymptomatic or have symptoms that are not very obvious. Due to incorrect diagnosis, the morbidity of parathyroid carcinomas remains high although they only account for $0.55 \%$ of all parathyroid tumors diagnosed (Schulte \& Talat 2012). Given the fact that DICER1 mutations are prevalent in many tumors of endocrine origin, its role in parathyroid tumors demands attention. Further research should aim to improve disease identification, leading to earlier diagnosis and, ideally, better prognosis for individuals with these tumors.

\section{Future directions and conclusions}

The discovery of DICER1 mutations and the resulting familial tumor predisposition syndrome has led to a surge in interest surrounding the DICER1 gene and its involvement in physiological and pathophysiological processes. As evident from a review of recent literature, DICER 1 mutations are particularly prevalent in tumors and cancers of endocrine origin and they should be considered a risk factor for these conditions especially when coupled with clinical suspicions such as concurrence PPB. While this line of research is still in its infancy, much progress has already been made in understanding how DICER 1 and miRNA signalling contributes to the pathogenesis of a variety of endocrine tumors. However, like any line of research in its early stages, there remain many questions to be answered.

First and foremost, a priority in this field should be to characterize DICER1 mutations in the less common endocrine tumors and those whose etiology is less well understood. Though it is well established that DICER1 mutations play a role in the development of pituitary blastoma, pineoblastoma, gonadal tumors and thyroid tumors, current research on DICER1 mutations in pancreatic, parathyroid, adrenomedullary tumors and paragangliomas is severely lacking or non-existent. If DICER1 mutations are identified in these tumors, it could lead to the discovery of a novel therapeutic target for them, which have few other viable treatments. Additionally, identification of DICER1 mutations in these tumors may allow for better classification of lesions that are currently unclassifiable or ambiguous in nature (Stewart et al. 2013, Witkowski et al. 2013). This will lead to faster and more accurate diagnoses by physicians, ultimately allowing for improved and more personalized patient care.

While the identification of DICER 1 mutations in endocrine tumors is a step in the right direction, future research should seek to determine the method by which the DICER1 gene is mutated and how this mutation contributes to the diseased state at the cellular/molecular level. There is currently controversy surrounding the mechanism by which DICER1 function is lost, specifically whether a classical two-hit theory applies to this gene. For example, in pituitary blastoma and pineoblastoma, a twohit model in which DICER1 acts as a tumor suppressor gene seems evident, while in Sertoli-Leydig cell tumors, DICER1 appears to act as a dominantly acting oncogene (Heravi-Moussavi et al. 2012, de Kock et al. 2014b, Sahakitrungruang et al. 2014). The notion that DICER1 mutations can have variable effects on different cell types is currently unclear, but is of great importance to understanding how DICER1 mutations lead to tumor development and to what extent they contribute. The study of DICER1-related tumors has, in general, shown an overarching consistent molecular pattern: germline mutations which are scattered throughout the gene domains, followed by highly specific somatic mutations on a few critical RNase IIIb domains. This was clearly demonstrated in the number of PPB and SLCT cases studied yet PitB and perhaps PinB may not follow this molecular pattern. Once this discrepancy has been resolved, future research should focus on the exact signaling pathways and molecular constituents that interact with DICER1 and how they are disrupted by DICER 1 mutations. Given the normal function of DICER1, it is likely that impaired miRNA signaling plays a critical role in tumor development. Whether targeting of the miRNA signaling system is a feasible or useful therapeutic option remains to be seen, but is a promising line of future research.

While the extent to which DICER1 mutations contribute to the development of endocrine tumors has not yet been fully established, there is no doubt that aberrant DICER1 signalling plays at least a small role in 
the pathogenesis of these diseases. Though research on this topic is still in its early stages, the mere presence of DICER 1 mutations in so many endocrine tumors suggests that this is a very promising path for future research. It is uncertain whether a better understanding of these mutations will lead to useful clinical interventions and/or treatments, but their prevalence is too great to be overlooked any longer.

\section{Declaration of interest}

The authors declare that there is no conflict of interest that could be perceived as prejudicing the impartiality of this review.

\section{Funding}

This work did not receive any specific grant from any funding agency in the public, commercial or not-for-profit sector.

\section{Acknowledgement}

Authors are grateful to the Jarislowsky and Lloyd Carr-Harris foundations for their continuous support.

\section{References}

Abuhatzira L, Xu H, Tahhan G, Boulougoura A, Schäffer AA \& Notkins AL 2015 Multiple microRNAs within the 14q32 cluster target the mRNAs of major type 1 diabetes autoantigens IA-2, IA-2 $\beta$, and GAD65. FASEB Journal 29 4374-4383. (https://doi.org/10.1096/ fj.15-273649)

Agrawal N, Akbani R, Aksoy BA, Ally A, Arachchi H, Asa SL, Auman JT, Balasundaram M, Balu S, Baylin SB, et al. 2014 Integrated genomic characterization of papillary thyroid carcinoma. Cell 159 676-690. (https://doi.org/10.1016/j.cell.2014.09.050)

Bernstein E, Caudy AA, Hammond SM \& Hannon GJ 2001 Role for a bidentate ribonuclease in the initiation step of RNA interference. Nature 409 363-366. (https://doi.org/10.1038/35053110)

Caramuta S, Lee L, Özata DM, Akçakaya P, Xie H, Höög A, Zedenius J, Bäckdahl M, Larsson C \& Lui WO 2013 Clinical and functional impact of TARBP2 over-expression in adrenocortical carcinoma. Endocrine-Related Cancer 20 551-564. (https://doi.org/10.1530/ERC13-0098)

Chendrimada TP, Gregory RI, Kumaraswamy E, Norman J, Cooch N, Nishikura K \& Shiekhattar R 2005 TRBP recruits the Dicer complex to Ago 2 for microRNA processing and gene silencing. Nature $\mathbf{4 3 6}$ 740-744. (https://doi.org/10.1038/nature03868)

Cohen A, Rovelli A, Merlo DF, van Lint MT, Lanino E, Besters D, Ceppi M, Bocchini V, Tichelli A \& Socie G 2007 Risk for secondary thyroid carcinoma after hematopoietic stem-cell transplantation: an EBMT Late Effects Working Party Study. Journal of Clinical Oncology 25 2449-2454. (https://doi.org/10.1200/JCO.2006.08.9276)

Costa V, Esposito R, Ziviello C, Sepe R, Bim LV, Cacciola NA, DecaussinPetrucci M, Pallante P, Fusco A \& Ciccodicola A 2015 New somatic mutations and WNK1-B4GALNT3 gene fusion in papillary thyroid carcinoma. Oncotarget 6 11242-11251. (https://doi.org/10.18632/ oncotarget.3593)

Criscimanna A, Speicher JA, Houshmand G, Shiota C, Prasadan K, Ji B, Logsdon CD, Gittes GK \& Esni F 2011 Duct cells contribute to regeneration of endocrine and acinar cells following pancreatic damage in adult mice. Gastroenterology 141 1451-1462. (https://doi. org/10.1053/j.gastro.2011.07.003)

Darrat I, Bedoyan JK, Chen M, Schuette JL \& Lesperance MM 2013 Novel DICER1 mutation as cause of multinodular goiter in children. Head and Neck 35 E369-E371. (https://doi.org/10.1002/hed.23250)

de Kock L, Sabbaghian N, Druker H, Weber E, Hamel N, Miller S, Choong CS, Gottardo NG, Kees UR, Rednam SP, et al. 2014a Germ-line and somatic DICER1 mutations in pineoblastoma. Acta Neuropathologica 128 583-595. (https://doi.org/10.1007/s00401-014-1318-7)

de Kock L, Sabbaghian N, Plourde F, Srivastava A, Weber E, Bouron-Dal Soglio D, Hamel N, Choi JH, Park SH, Deal CL, et al. 2014b Pituitary blastoma: a pathognomonic feature of germ-line DICER1 mutations. Acta Neuropathologica 128 111-122. (https://doi.org/10.1007/s00401014-1285-z)

de Kock L, Sabbaghian N, Soglio DBD, Guillerman RP, Park BK, Chami R, Deal CL, Priest JR \& Foulkes WD 2014c Exploring the association between DICER1 mutations and differentiated thyroid carcinoma. Journal of Clinical Endocrinology and Metabolism 99 E1072-E1077. (https://doi.org/10.1210/jc.2013-4206)

de Kock L, Terzic T, McCluggage WG, Stewart CJR, Shaw P, Foulkes WD \& Clarke BA 2017 DICER1 mutations are consistently present in moderately and poorly differentiated Sertoli-Leydig cell tumors. American Journal of Surgical Pathology 41 1178-1187. (https://doi. org/10.1097/PAS.0000000000000895)

de Sousa GRV, Ribeiro TC, Faria AM, Mariani BMP, Lerario AM, Zerbini MCN, Soares IC, Wakamatsu A, Alves VAF, Mendonca BB, et al. 2015 Low DICER1 expression is associated with poor clinical outcome in adrenocortical carcinoma. Oncotarget 6 22724-22733. (https://doi.org/10.18632/oncotarget.4261)

Erler P, Keutgen XM, Crowley MJ, Zetoune T, Kundel A, Kleiman D, Beninato T, Scognamiglio T, Elemento O, Zarnegar R, et al. 2014 Dicer expression and microRNA dysregulation associate with aggressive features in thyroid cancer. Surgery 156 1342-1350. (https://doi.org/10.1016/j.surg.2014.08.007)

Eser S, Schnieke A, Schneider G \& Saur D 2014 Oncogenic KRAS signalling in pancreatic cancer. British Journal of Cancer 111 817-822. (https://doi.org/10.1038/bjc.2014.215)

Espiard S, Ragazzon B \& Bertherat J 2014 Protein kinase A alterations in adrenocortical tumors. Hormone and Metabolic Research 46 869-875. (https://doi.org/10.1055/s-0034-1385908)

Faillot S \& Assie G 2016 Endocrine tumours: the genomics of adrenocortical tumors. European Journal of Endocrinology $\mathbf{1 7 4}$ R249-R265. (https://doi.org/10.1530/EJE-15-1118)

Foulkes WD, Priest JR \& Duchaine TF 2014 DICER1: mutations, microRNAs and mechanisms. Nature Reviews Cancer 14 662-672. (https://doi.org/10.1038/nrc3802)

Gheorghisan-Galateanu A, Fica S, Terzea DC, Caragheorgheopol A \& Horhoianu V 2003 Sertoli-Leydig cell tumor - a rare androgen secreting ovarian tumor in postmenopausal women: case report and review of literature. Journal of Cellular and Molecular Medicine 7 461-471.

Goulvent T, Ray-Coquard I, Borel S, Haddad V, DevouassouxShisheboran M, Vacher-Lavenu MC, Pujade-Laurraine E, Savina A Maillet D, Gillet G, et al. 2016 DICER1 and FOXL2 mutations in ovarian sex cord-stromaltumours: a GINECO Group study. Histopathology 68 279-285. (https://doi.org/10.1111/his.12747)

Heravi-Moussavi A, Anglesio MS, Cheng S-WG, Senz J, Yang W, Prentice L, Fejes AP, Chow C, Tone A, Kalloger SE, et al. 2012 Recurrent somatic DICER1 mutations in nonepithelial ovarian cancers. New England Journal of Medicine 366 234-242. (https://doi. org/10.1056/NEJMoa1102903)

Hill DA, Ivanovich J, Priest JR, Gurnett CA, Dehner LP, Desruisseau D, Jarzembowski JA, Wikenheiser-Brokamp KA, Suarez BK, Whelan AJ, et al. 2009 DICER1 mutations in familial pleuropulmonary blastoma. Science 325 965. (https://doi.org/10.1126/science.1174334) 
Huang C-CJ \& Yao HHC 2010 Inactivation of Dicer1 in Steroidogenic factor 1-positive cells reveals tissue-specific requirement for Dicer1 in adrenal, testis, and ovary. BMC Developmental Biology 10 66. (https:// doi.org/10.1186/1471-213X-10-66)

Huang CC, Liu C \& Yao HH 2012 Investigating the role of adrenal cortex in organization and differentiation of the adrenal medulla in mice. Molecular and Cellular Endocrinology 361 165-171. (https://doi. org/10.1016/j.mce.2012.04.004)

Kalis M, Bolmeson C, Esguerra JLS, Gupta S, Edlund A, Tormo-Badia N, Speidel D, Holmberg D, Mayans S, Khoo NKS, et al. 2011 Beta-cell specific deletion of dicer1 leads to defective insulin secretion and diabetes mellitus. PLOS ONE 6 e29166. (https://doi.org/10.1371/ journal.pone.0029166)

Kanji MS, Martin MG \& Bhushan A 2013 Dicer1 is required to repress neuronal fate during endocrine cell maturation. Diabetes 62 1602-1611. (https://doi.org/10.2337/db12-0841)

Kim MS, Lee SH, Yoo NJ \& Lee SH 2013 DICER1 exons 25 and 26 mutations are rare in common human tumours besides SertoliLeydig cell tumour. Histopathology 63 436-438. (https://doi. org/10.1111/his.12161)

Kirmani S \& Young WF 2008 Hereditary paragangliomapheochromocytoma syndromes. In GeneReviews. Seattle, WA, USA University of Washington. (available from: https://www.ncbi.nlm. nih.gov/books/NBK1548/)

Krill KT, Gurdziel K, Heaton JH, Simon DP \& Hammer GD 2013 Dicer deficiency reveals microRNAs predicted to control gene expression in the developing adrenal cortex. Molecular Endocrinology 27 754-768. (https://doi.org/10.1210/me.2012-1331)

Lambertz I, Nittner D, Mestdagh P, Denecker G, Vandesompele J, Dyer MA \& Marine JC 2010 Monoallelic but not bialleleic loss of DICER 1 promotes tumorigenesis in vivo. Cell Death and Differentiation 17 633-641. (https://doi.org/10.1038/ cdd.2009.202)

Landa I, Ibrahimpasic T, Boucai L, Sinha R, Knauf JA, Shah RH, Dogan S, Ricarte-Filho JC, Krishnamoorthy GP, Xu B, et al. 2016 Genomic and transcriptomic hallmarks of poorly differentiated and anaplastic thyroid cancers. Journal of Clinical Investigation 126 1052-1066. (https://doi.org/10.1172/JCI85271)

Lloyd RV 2011 Adrenal cortical tumors, pheochromocytomas and paragangliomas. Modern Pathology 24 (Supplement 2) S58-S65. (https://doi.org/10.1038/modpathol.2010.126)

Locke JM \& Harries LW 2012 MicroRNA expression profiling of human islets from individuals with and without type 2 diabetes: promises and pitfalls. Biochemical Society Transactions 40 800-803. (https://doi. org/10.1042/BST20120049)

Lynn FC, Skewes-Cox P, Kosaka Y, McManus MT, Harfe BD \& German MS 2007 MicroRNA expression is required for pancreatic islet cell genesis in the mouse. Diabetes 56 2938-2945. (https://doi. org/10.2337/db07-0175)

Mandelbaum AD, Melkman-Zehavi T, Oren R, Kredo-Russo S, Nir T, Dor Y \& Hornstein E 2012 Dysregulation of Dicer1 in beta cells impairs islet architecture and glucose metabolism. Experimental Diabetes Research 2012 470302. (https://doi. org/10.1155/2012/470302)

Melkman-Zehavi T, Oren R, Kredo-Russo S, Shapira T, Mandelbaum AD, Rivkin N, Nir T, Lennox KA, Behlke MA, Dor Y, et al. 2011 miRNAs control insulin content in pancreatic $\beta$-cells via downregulation of transcriptional repressors. EMBO Journal 30 835-845. (https://doi. org/10.1038/emboj.2010.361)

Melo SA, Ropero S, Moutinho C, Aaltonen LA, Yamamoto H, Calin GA, Rossi S, Fernandez AF, Carneiro F, Oliveira C, Ferreira B, Liu CG, et al 2009 A TARBP2 mutation in human cancer impairs microRNA processing and DICER1 function. Nature Genetics 41 365-370. (https://doi.org/10.1038/ng.317)

Mertens WC, Grignon DJ \& Romano W 1993 Malignant paraganglioma with skeletal metastases and spinal cord compression: response and palliation with chemotherapy. Clinical Oncology 5 126-128. (https:// doi.org/10.1016/S0936-6555(05)80868-4)

Morita S, Hara A, Kojima I, Horii T, Kimura M, Kitamura T, Ochiya T, Nakanishi K, Matoba R, Matsubara K, et al. 2009 Dicer is required for maintaining adult pancreas. PLOS ONE 4 e4212. (https://doi. org/10.1371/journal.pone.0004212)

Morris JP 4th, Greer R, Russ HA, von Figura G, Kim GE, Busch A, Lee J, Hertel KJ, Kim S, McManus M, et al. 2014 Dicer regulates differentiation and viability during mouse pancreatic cancer initiation. PLOS ONE 9 e95486. (https://doi.org/10.1371/journal. pone.0095486)

Nicholson A 2008 Epidemiology of endocrine tumors. In Clinical Endocrine Oncology, 2nd ed., pp 18-23. EdsHay ID \&Wass JAH. Malden, MA, USA: Blackwell Publishing.

Oost EE, Charles A, Choong CS, Leung YC, Salfinger S, Sonnendecker H, Tan J, Townshend S, Witkowski L, Foulkes WD, et al. 2015 Ovarian sex cord-stromal tumors in patients with probable or confirmed germline DICER1 mutations. International Journal of Gynecological Pathology 34 266-274. (https://doi.org/10.1097/ PGP.0000000000000150)

Osamura RY, Lopes MBS, Grossman A, Matsuno A, Korbonits M, Trouillas J \& Kovacs K 2017 Pituitary adenoma. In WHO Classification of Tumours of Endocrine Organs, 4th ed., pp 14-18. Eds Lloyd RV, Osamura RY, Klöppel G \& Rosai J. Lyon, France: IARC Press.

Özcan S 2015 microRNAs in pancreatic $\beta$-cell physiology. Advances in Experimental Medicine and Biology 887 101-117. (https://doi. org/10.1007/978-3-319-22380-3_6)

Raleigh DR, Solomon DA, Lloyd SA, Lazar A, Garcia MA, Sneed PK, Clarke JL, McDermott MW, Berger MS, Tihan T, et al. 2017 Histopathologic review of pineal parenchymal tumors identifies novel morphologic subtypes and prognostic factors for outcome. Neuro-Oncology 19 78-88. (https://doi.org/10.1093/neuonc/now105)

Rath SR, Bartley A, Charles A, Powers N, Baynam G, Jones T, Priest JR, Foulkes WD \& Choong CS 2014 Multinodular Goiter in children: an important pointer to a germline DICER1 mutation. Journal of Clinical Endocrinology and Metabolism 99 1947-1948. (https://doi. org/10.1210/jc.2013-3932)

Ravi A, Gurtan A, Kumar M, Bhutkar A, Chin C, Lu V, Lees JA, Jacks T \& Sharp PA 2012 Proliferation and tumorigenesis of a murine sarcoma cell line in the absence of DICER1. Cancer Cell 21 845-855. (https:// doi.org/10.1016/j.ccr.2012.04.037)

Rio Frio T, Bahubeshi A, Kanellopoulou C, Hamel N, Niedziela M, Sabbaghian N, Pouchet C, Gilbert L, O'Brien PK, Serfas K, et al. 2011 DICER1 mutations in familial multinodular goiter with and without ovarian Sertoli-Leydig cell tumors. JAMA 305 68-77. (https://doi. org/10.1001/jama.2010.1910)

Robertson S, MacKenzie SM, Alvarez-Madrazo S, Diver LA, Lin J, Stewart PM, Fraser R, Connell JM \& Davies E 2013 MicroRNA-24 is a novel regulator of aldosterone and cortisol production in the human adrenal cortex. Hypertension 62 572-578. (https://doi.org/10.1161/ HYPERTENSIONAHA.113.01102)

Rossing M, Gerdes A-M, Juul A, Rechnitzer C, Rudnicki M, Nielsen FC \& Vo Hansen T 2014 A novel DICER1 mutation identified in a female with ovarian Sertoli-Leydig cell tumor and multinodular goiter: a case report. Journal of Medical Case Reports 8 112. (https://doi. org/10.1186/1752-1947-8-112)

Rotondo F, Syro LV, Lloyd RV, Foulkes WD \& Kovacs K 2017 Pituitary blastoma In. WHO Classification of Tumours of Endocrine Organs, 4th ed., pp 45. Eds Lloyd RV, Osamura RY, Klöppel G \& Rosai J. Lyon, France: IARC Press.

Rutter MM, Jha P, Schultz KAP, Sheil A, Harris AK, Bauer AJ, Field AL, Geller J \& Hill DA 2016 DICER1 mutations and differentiated thyroid carcinoma: evidence of a direct association. Journal of Clinical Endocrinology and Metabolism 101 1-5. (https://doi. $\operatorname{org} / 10.1210 /$ jc.2015-2169)
(2) 2018 Society for Endocrinology Published by Bioscientifica Ltd. Printed in Great Britain 
Sabbaghian N, Hamel N, Srivastava A, Albrecht S, Priest JR \& Foulkes WD 2012 Germline DICER1 mutation and associated loss of heterozygosity in a pineoblastoma. Journal of Medical Genetics $\mathbf{4 9}$ 417-419. (https://doi.org/10.1136/jmedgenet-2012-100898)

Sahakitrungruang T, Srichomthong C, Pornkunwilai S, Amornfa J, Shuangshoti S, Kulawonganunchai S, Suphapeetiporn K \& Shotelersuk V 2014 Germline and somatic DICER1 mutations in a pituitary blastoma causing infantile-onset Cushing's disease. Journal of Clinical Endocrinology and Metabolism 99 1487-1492. (https://doi. org/10.1210/jc.2014-1016)

Scheithauer BW, Kovacs K, Horvath E, Kim DS, Osamura RY, Ketterling RP, Lloyd RV \& Kim OL 2008 Pituitary blastoma. Acta Neuropathologica 116 657-666. (https://doi.org/10.1007/s00401-008-0388-9)

Scheithauer BW, Horvath E, Abel TW, Robital Y, Park SH, Osamura RY, Deal C, Lloyd RV \& Kovacs K 2012 Pituitary blastoma: a unique embryonal tumor. Pituitary 15 365-373. (https://doi.org/10.1007/ s11102-011-0328-x)

Schulte KM \& Talat N 2012 Diagnosis and management of parathyroid cancer. Nature Reviews Endocrinology 8 612-622. (https://doi. org/10.1038/nrendo.2012.102)

Schultz KA, Pacheco MC, Yang J, Williams GM, Messinger Y, Hill DA, Dehner LP \& Priest JR 2011 Ovarian sex cord-stromal tumors, pleuropulmonary blastoma and DICER1 mutations: a report from the International Pleuropulmonary Blastoma Registry. Gynecologic Oncology 122 246-250. (https://doi.org/10.1016/j.ygyno.2011.03.024)

Schultz KA, Harris A, Williams GM, Baldinger S, Doros L, Valusek P, Frazier AL, Dehner LP, Messinger Y \& Hill DA 2014 Judicious DICER1 testing and surveillance imaging facilitates early diagnosis and cure of pleuropulmonary blastoma. Pediatric Blood and Cancer $\mathbf{6 1}$ 1695-1697. (https://doi.org/10.1002/pbc.25092)

Shilo V, Ben-Dov IZ, Nechama M, Silver J \& Naveh-Many T 2015 Parathyroid-specific deletion of dicer-dependent microRNAs abrogates the response of the parathyroid to acute and chronic hypocalcemia and uremia. FASEB Journal 29 3964-3976. (https://doi. org/10.1096/fj.15-274191)

Shin SH, Yoon JH, Son MH, Kim S-J, Park S-Y, Kim HY, Lee H-S, Park HJ \& Park B-K 2012 Follicular thyroid carcinoma arising after hematopoietic stem cell transplantation in a child with pleuropulmonary blastoma. Thyroid 22 547-551. (https://doi. org/10.1089/thy.2011.0161)

Smith JJ, Chen X, Schneider DF, Broome JT, Sippel RS, Chen H \& Solórzano CC 2013 Cancer after thyroidectomy: a multi-institutional experience with 1523 patients. Journal of the American College of Surgeons 216 571-579. (https://doi.org/10.1016/j.jamcollsurg.2012.12.022)

Stewart CJR, Alexiadis M, Crook ML \& Fuller PJ 2013 An immunohistochemical and molecular analysis of problematic and unclassified ovarian sex cord-stromal tumors. Human Pathology 44 2774-2781. (https://doi.org/10.1016/j.humpath.2013.07.028)

Tattikota SG \& Poy MN 2011 Re-dicing the pancreatic $\beta$-cell: do microRNAs define cellular identity? EMBO Journal 30 797-799. (https://doi.org/10.1038/emboj.2011.31)

Taylor AJ, Croft AP, Palace AM, Winter DL, Reulen RC, Stiller CA, Stevens MC \& Hawkins MM 2009 Risk of thyroid cancer in survivors of childhood cancer: results from the British Childhood Cancer Survivor Study. International Journal of Cancer 125 2400-2405. (https://doi.org/10.1002/ijc.24581)

Terzolo M, Daffara F, Ardito A, Zaggia B, Basile V, Ferrari L \& Berruti A 2014 Management of adrenal cancer: a 2013 update. Journal of Endocrinological Investigation 37 207-217. (https://doi.org/10.1007/ s40618-013-0049-2)

Toledo RA, \& Dahia PL 2015 Next-generation sequencing for the diagnosis of hereditary pheochromocytoma and paraganglioma syndromes. Current Opinion in Endocrinology, Diabetes and Obesity 22 169-179. (https://doi.org/10.1097/MED.0000000000000150)

Trombetta M, Silverman J, Colonias A, Lee V, Mohanty A \& Parda D 2008 Paraganglioma: a potentially challenging tumor. Oncology 22 341-343.

Van Nieuwenhuysen E, Lambrechts S, Lambrechts D, Leunen K, Amant F \& Vergote I 2013 Genetic changes in nonepithelial ovarian cancer. Expert Review of Anticancer Therapy 13 871-882. (https://doi. org/10.1586/14737140.2013.811174)

Wang X, Zhao J, Huang J, Tang H, Yu S \& Chen Y 2012 The regulatory roles of miRNA and methylation on oncogene and tumor suppressor gene expression in pancreatic cancer cells. Biochemical and Biophysical Research Communications 425 51-57. (https://doi. org/10.1016/j.bbrc.2012.07.047)

Wang YJ, McAllister F, Bailey JM, Scott SG, Hendley AM, Leach SD \& Ghosh B 2014 Dicer is required for maintenance of adult pancreatic acinar cell identity and plays a role in Kras-driven pancreatic neoplasia. PLoS ONE 9 e113127. (https://doi.org/10.1371/journal. pone.0113127)

Wang Y, Chen J, Yang W, Mo F, Senz J, Yap D, Anglesio MS, Gilks B, Morin GB \& Huntsman DG 2015 The oncogenic roles of DICER1 RNase IIIb domain mutations in ovarian Sertoli-Leydig cell tumors. Neoplasia 17 650-660. (https://doi.org/10.1016/j.neo.2015.08.003)

Winter C \& Albers P 2011 Testicular germ cell tumors: pathogenesis, diagnosis and treatment. Nature Reviews Endocrinology 7 43-53. (https://doi.org/10.1038/nrendo.2010.196)

Witkowski L, Mattina J, Schönberger S, Murray MJ, Choong CS, Huntsman DG, Reis-Filho JS, McCluggage WG, Nicholson JC, Coleman N, et al. 2013 DICER1 hotspot mutations in non-epithelial gonadal tumours. British Journal of Cancer 109 2744-2750. (https:// doi.org/10.1038/bjc.2013.637)

Wu Y, Chen D, Li Y, Bian L, Ma T \& Xie M 2014 DICER1 mutations in a patient with an ovarian Sertoli-Leydig tumor, well-differentiated fetal adenocarcinoma of the lung, and familial multinodular goiter. European Journal of Medical Genetics 57 621-625. (https://doi. org/10.1016/j.ejmg.2014.09.008)

Yoo SK, Lee S, Kim SJ, Jee HG, Kim BA, Cho H, Song YS, Cho SW, Won JK, Shin JY, et al. 2016 Comprehensive analysis of the transcriptional and mutational landscape of follicular and papillary thyroid cancers. PLoS Genetics 12 e1006239. (https://doi.org/10.1371/ journal.pgen.1006239)

Zak FG \& Lawson W 1982 The Paraganglionic Chemoreceptor System: Physiology, Pathology, and Clinical Medicine, pp 1-479. New York, NY, USA: Springer-Verlag.

Received in final form 9 January 2018

Accepted 11 January 2018

Accepted Preprint published online 12 January 2018 http://ercendocrinology-journals.org https://doi.org/10.1530/ERC-17-0509 (c) 2018 Society for Endocrinology Published by Bioscientifica Ltd. Printed in Great Britain 